\title{
Adaptive Responses to Electrophilic Stress and Reactive Sulfur Species as their Regulator Molecules
}

\author{
Yoshito Kumagai ', Masahiro Akiyama' and Takamitsu Unoki ${ }^{2}$ \\ ${ }^{1}$ Environmental Biology Laboratory, Faculty of Medicine, University of Tsukuba, Ibaraki, Japan \\ ${ }^{2}$ Department of Basic Medical Sciences, National Institute for Minamata Disease, Kumamoto, Japan
}

\begin{abstract}
We are exposed to numerous xenobiotic electrophiles on a daily basis through the environment, lifestyle, and dietary habits. Although such reactive species have been associated with detrimental effects, recent accumulated evidence indicates that xenobiotic electrophiles appear to act as signaling molecules. In this review, we introduce our findings on 1) activation of various redox signaling pathways involved in cell proliferation, detoxification/ excretion of electrophiles, quality control of cellular proteins, and cell survival during exposure to xenobiotic electrophiles at low concentrations through covalent modification of thiol groups in sensor proteins, and 2) negative regulation of reactive sulfur species (RSS) in the modulation of redox signaling and toxicity caused by xenobiotic electrophiles.
\end{abstract}

Key words: Electrophiles, Covalent modification, Redox signaling, Reactive sulfur species

\section{INTRODUCTION}

To lead richer lives, we seek jobs and places to live, as well as eat meals, as we strive to maintain our health and wellbeing. Food preferences vary from individual to individual with some people eating mainly meat, whereas others are vegetarians. In addition, some people smoke and eat between meals to avoid stress. Chronically maintaining such complex environmental factors causes a presymptomatic health status (a condition in which diseases are not diagnosed, but cannot be regarded as healthy), eventually resulting in the development of diseases. Our laboratory focuses on xenobiotic electrophiles as reactive

Correspondence to: Yoshito Kumagai, Environmental Biology Laboratory, Faculty of Medicine, University of Tsukuba, 1-1-1 Tennodai, Tsukuba, Ibaraki 305-8575, Japan

E-mail: yk-em-tu@md.tsukuba.ac.jp

This is an Open-Access article distributed under the terms of the Creative Commons Attribution Non-Commercial License (http:// creativecommons.org/licenses/by-nc/3.0) which permits unrestricted non-commercial use, distribution, and reproduction in any medium, provided the original work is properly cited.

Abbreviations: (MeHg) ${ }_{2} \mathrm{~S}$, Bismethylmercury sulfide; 1,2-NQ, 1,2Napthoquinone; 1,4-NQ, 1,4-Napthoquinone; 3MST, 3-Mercaptopyruvate sulfurtransferase; 8-nitro-cGMP, 8-nitroguanosine 3',5'cyclic monophosphate; Bcl-2, B-cell lymphoma 2; CARS2, Cyste- chemical substances that enter the body through diet, environment, and lifestyle. For example, 1,2-naphthoquinone (1,2-NQ) and 1,4-naphthoquinone (1,4-NQ) are produced during the combustion of fuels and both contaminate as air pollutants in PM2.5 particles and volatile fractions of air (1-4). Additionally, 1,4-benzoquinone and crotonaldehyde are constituents of tobacco smoke $(5,6)$, while $(E)$-2-alkenals are found in vegetables and herbs such as coriander (7). Acrylamide is found in certain heat-processed foods such as potato chips (8). Methylmercury ( $\mathrm{MeHg}$ ), the causative agent of Minamata disease that is considered as one of Japan's four major pollution-caused diseases, accumulates in large edible fish, such as tuna, through the food

ine-tRNA synthetase; CBS, cystathionine $\beta$-synthase; $C d$, Cadmium; CREB, CAMP response element binding protein; CSE, Cystathionine $\gamma$-lyase; CysSSCys, Cysteine; CysSSH, Cysteine persulfide; EGFR, Epidermal growth factor receptor; EpRE, Electrophile response element; GCL, Glutamate cysteine ligase; GSH, Glutathione; GSSH, Glutathione persulfide; GSSnH, GSH polysulfide; GST, GSH S-transferase; $\mathrm{H}_{2} \mathrm{~S}$, Hydrogen sulfide; HO-1, Heme oxygenase-1; HSF1, Heat shock factor 1; HSP90, Heat shock protein 90; IARC, International Agency for Research on Cancer; Keap1, Kelch-like ECH-associated protein 1; MeHg, Methylmercury; MRP, Multidrug resistance-associated protein; NAPQI, Nacetyl-p-benzoquinone; Nrf2, NF-E2-related factor 2; PTP1B, Protein tyrosine pho- sphatase $1 \mathrm{~B}$; ROS, Reactive oxygen species; RSS, Reactive sulfur species. 

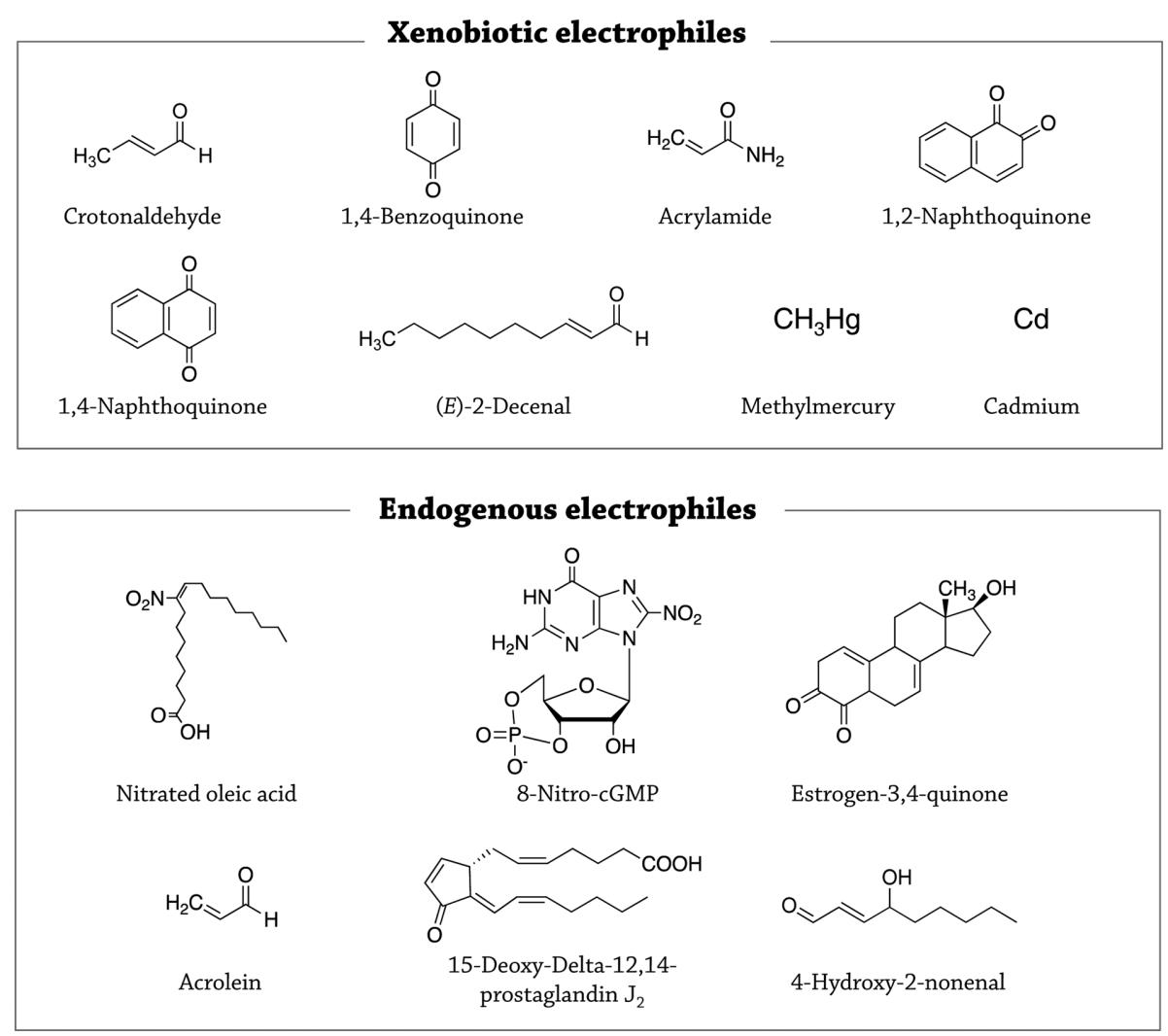

Fig. 1. Structures of representative xenobiotic and endogenous electrophiles. We are routinely exposed to electrophilic stress by a large number of diverse xenobiotic electrophiles in the environment. However, various endogenous electrophiles have been identified. Recent accumulated evidence indicates that both xenobiotic and endogenous electrophiles appear to act as signaling molecules.

chain and bioaccumulation $(9,10)$. Moreover, cadmium $(\mathrm{Cd})$, is well known as the causative agent of the so-called Itai-Itai disease, another of the four major pollutioncaused diseases, which is contained in rice $(11,12)$. Thus, we are routinely exposed to electrophilic stress. Fig. 1 shows xenobiotic electrophiles examined in our laboratory, although there is a very large number of electrophiles in the environment.

\section{ARE ELECTROPHILES GOOD OR BAD?}

Electrophiles have low electron-density sites that form adducts by covalently binding to nucleophilic substituents such as high electron-density DNA guanine residues and protein cysteine residues. There are many studies demonstrating that adduct formation of such macromolecules causes cancer and tissue injury, which indicates that electrophiles have long been perceived as unhealthy. For example, Katsusaburo Yamagiwa, a Professor at the Department of Pathology, University of Tokyo School of Medicine, induced squamous cell carcinoma by painting coal tar, which contains numerous chemicals such as benzopyrene, on the inner surface of rabbit ears in 1915 (13). Subsequently, another group reported that benzopyrene itself is inactive, but undergoes metabolic activation mediated by microsomal enzymes, forming its dihydrodiol epoxide that is unstable and rapidly converted into an electrophilic metabolite $(14,15)$. As a result, this electrophile covalently reacts with nucleophilic moieties of DNA, resulting in the formation of DNA adducts involved in carcinoma $(14,15)$. Bernard B. Brodie, who established the Laboratory of Chemical Pharmacology in the 1950s, is known as the father of modern pharmacology (16). Brodie predicted the mechanism-of-action of hepatic necrosis by overdoses of acetaminophen and bromobenzene in 1971 (17). These chemicals undergo biotransformation, yielding electrophilic metabolites that covalently bind to the abundant small nucleophile glutathione (GSH), leading to the GSH adducts associated with detoxification of these chemicals (18). However, overdoses of the chemicals cause substantial depletion of GSH in the liver. Thus, hepatic protein thiol becomes the molecular target of the electrophilic metabolites (18). Therefore, this protein adduct has been thought to be linked to hepatic necrosis.

However, in 1990, Violet Daniel and associates in the U.S. found that treatment of cultured cells with electrophiles upregulates phase-II xenobiotic-metabolizing enzymes through the electrophile-responsive element (EpRE) (19). 
Nine years later, Masayuki Yamamoto and associates discovered that electrophiles modify Kelch-like ECH-associated protein 1 (Keap1) thiols, resulting in inhibition of its activity to bind the transcription factor NF-E2-related factor 2, Nrf2, thereby facilitating its nuclear translocation (20). Nrf2 interacts with its partner proteins, small Maf to form a heterodimer complex that binds to the EpRE, suggesting that electrophiles have a beneficial effect (21).

On the other hand, various endogenous electrophiles have been discovered as shown in Fig. 1. For example, Harald Esterbauer (22), Bruce A. Freeman (23), and Takaaki Akaike (24) discovered 4-hydoxynonenal, nitrated fatty acids, and 8-nitroguanosine 3',5'-cyclic monophosphate (8-nitrocGMP), respectively. Interestingly, these endogenous electrophiles modify Keap1 and activate Nrf2 (25-27), suggesting that they act as cellular signaling molecules.

\section{MODULATION OF REDOX SIGNALING PATHWAYS THROUGH COVALENT MODIFICATION OF SENSOR PROTEINS}

It is well recognized that, although there are 214,000 cysteine residues in the human genome, $80 \%-90 \%$ of them are used for SH groups, S-S bonds, or ligands for zinc, and it is suggested that the remaining $10 \%-20 \%$ exist as deprotonated thiolate ions (28). In addition, it has been reported that there are multiple redox signaling pathways in cells, consisting of sensor proteins containing thiolate ions and effector molecules such as kinases and transcription factors (29-31). Under basal conditions, sensor proteins negatively regulate effector molecules. Under oxidative stress and inflammation conditions, such sensor proteins readily undergo oxidative modification by reactive oxygen species (ROS), suppressing their activities and thereby substantially activating effector molecules (32-38). Therefore, we theorized that xenobiotic electrophiles may selectively modify sensor proteins through thiolate ions at low doses and thus inhibit their activities to activate effector molecules (29). Our findings are based on the activation of cellular redox signaling pathways during exposure to xenobiotic electrophiles as detailed below.

Protein tyrosine phosphatase 1B (PTP1B) is responsible for dephosphorylation reactions and epidermal growth factor receptor (EGFR) is a kinase and substrate of PTP1B. PTP1B/EGFR signaling plays a role in cell proliferation (39). We found that 1,2-NQ modifies PTP1B through Cys121 in A431 cells, suppressing its catalytic activity and stimulating phosphorylation of EGFR (40). Such EGFR activation coupled with inhibition of PTP1B activity is also seen in HepG2 cells and primary hepatocytes (41) in addition to EGFR activation mediated by $\mathrm{MeHg}$ in human brain microvascular endothelial cells (42).

Under basal conditions, Nrf2 undergoes degradation by the ubiquitin-proteasome system, leading to a minimal level of Nrf2 in the cells. During oxidative and electrophilic stresses, Keap1, which is an adapter protein for ubiquitin E3 lyase Cullin 3, is oxidatively and chemically modified through reactive thiols presumably corresponding to thiolate ions, thereby diminishing its activity to bind to Nrf2. As a result, newly synthesized Nrf2 upregulates its downstream proteins through transactivation of the EpRE (21). The Keap1/Nrf2 system co-operatively regulates adaptive responses to oxidative stress and electrophilic stresses (34). Xenobiotic electrophiles 1,2-NQ, crotonaldehyde, $\mathrm{MeHg}$, and Cd modify Keap1 through Cys151 and activate Nrf2, thereby increasing the protein levels of antioxidant proteins such as hemeoxygenase-1 (HO-1) and glutamate cysteine ligase (GCL) to synthesize GSH, as well as phase-II xenobiotic-metabolizing enzymes [e.g., GSH $S$-transferases (GSTs) and UDP-glucuronosyltransferase] and phase III transporters such as multi-drug resistance-associated protein (MRP) (21,43-49).

Heat shock protein 90 (HSP90) is an interacting molecule of transcription factor heat shock factor 1 (HSF1). HSP90/HSF1 is a redox signal for quality control of cellular proteins (32). First, 2D SDS-PAGE and immunoblot analysis with a specific antibody against 1,4-NQ revealed that HSP90 is a molecular target of 1,4-NQ (50). Second, we found that 1,4-NQ and Cd modify HSP90 through Cys412 and Cys564, leading to substantial nuclear translocation of HSF1 by blocking its activity to bind HSF1 in the cytoplasm of A431 and bovine aortic endothelial cells, respectively. As a result, these xenobiotic electrophiles activate heat shock transcription factors $(51,52)$.

Phosphatase and tensin homolog (PTEN) is a protein phosphatase, and Akt negatively regulated by PTEN is a protein kinase (53). PTEN/Akt signaling is important for cell survival (53). We have reported that 1,4-NQ and $\mathrm{MeHg}$ selectively modify PTEN through Cys 71 and Cys 83 at low doses, diminishing its enzymatic activity and activating Akt and its downstream transcription factor, cAMP response element-binding protein (CREB) that regulates gene expression of antiapoptotic protein B-cell lymphoma 2 (Bcl-2) (54-56). Under these conditions, pre-treatment with a specific inhibitor of PI3K/Akt signaling significantly enhances cytotoxicity mediated by $\mathrm{MeHg}$, suggesting that activation of $\mathrm{Akt} / \mathrm{CREB} / \mathrm{Bcl}-2$ signaling by $\mathrm{MeHg}$ is essential for repression of its cytotoxicity (54). We also showed that $\mathrm{MeHg}$ at increasing doses modifies CREB through Cys286 and thus represses the interaction between CREB and CREB bound to MeHg in SH-SY5Y cells (54). We also found that the target amino acid residue in the interaction of 1,2-NQ with CREB is Cys286 (57). Bcl-2 was significantly downregulated under the conditions in which we detected covalent modification of CREB by 1,2NQ (57). Therefore, increasing doses of xenobiotic electrophiles cause extensive and non-selective modification of cellular proteins associated with cytotoxicity. Therefore, 


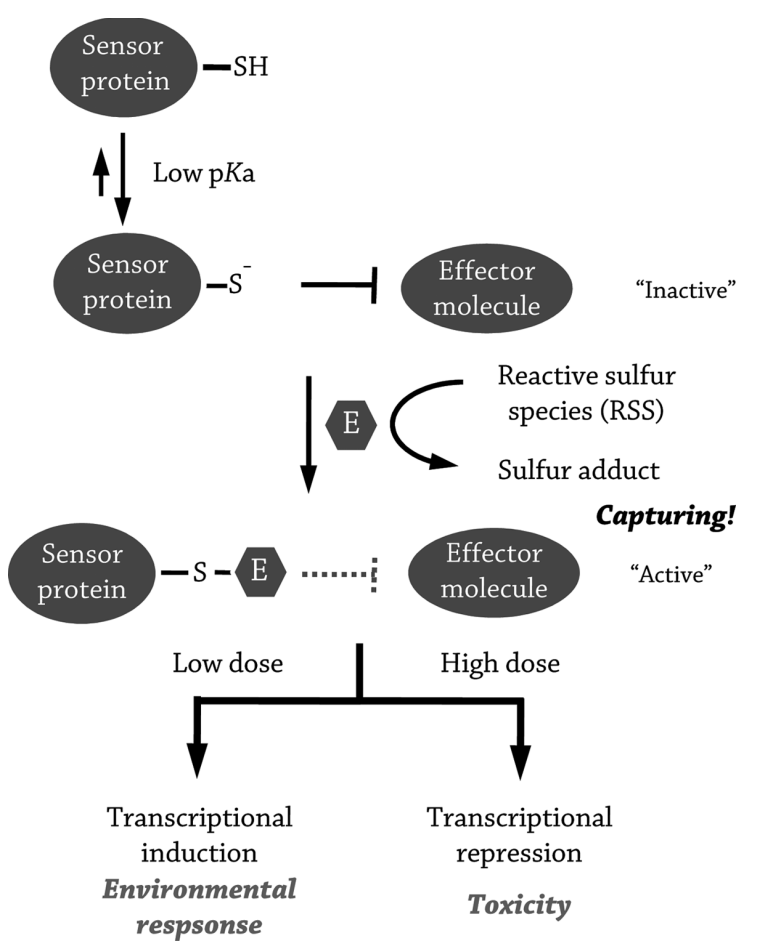

Fig. 2. Modulation of redox signaling pathways by xenobiotic electrophiles. Two different aspects of xenobiotic electrophiles: xenobiotic electrophile-mediated activation (low dose) and disruption (high dose) of redox signaling by sensor proteins with low $\mathrm{p} K_{\mathrm{a}}$ thiols and effector molecules that are negatively regulated by RSS through sulfur adduct formation. E, xenobiotic electrophiles; RSS, reactive sulfur species.

we speculate that modulation of the PTEN/Akt/CREB/ $\mathrm{Bcl}-2$ signaling pathway by $\mathrm{MeHg}$ is a typical example of a xenobiotic electrophile with two different aspects as shown in Fig. 2.

\section{REACTIVE SULFUR SPECIES AS POTENTIAL REGULATORS THAT REPRESS REACTIVITY OF XENOBIOTIC ELECTROPHILES}

GSH produced by GCL (58) is an abundant antioxidant, but the $\mathrm{p} K_{\mathrm{a}}$ value of its cysteine residue is 9.12 , indicating that approximately $2 \%$ of GSH exists in its deprotonated form, $\mathrm{GS}^{-}$, which is an electrophile at physiological $\mathrm{pH}$. However, GSTs are thought to facilitate the formation of electrophile-GSH adducts by lowering the $\mathrm{p} K_{\mathrm{a}}$ value of GSH $(59,60)$. The formed GSH adducts are in turn excreted into extracellular spaces through MRP $(61,62)$. Nrf2 is a molecule critical to the detoxification and excretion of xenobiotic electrophiles because this transcription factor cooperatively regulates the gene expression of GCL, GST, and MRP $(21,46)$ as shown in Fig. 3.

Although hydrogen sulfide $\left(\mathrm{H}_{2} \mathrm{~S}\right)$ has been extensively recognized as a harmful odorous gas, several lines of evidence indicate that endogenously produced $\mathrm{H}_{2} \mathrm{~S}$ plays a role in the repression of cardiovascular and neuronal diseases $(63,64)$. Interestingly, the $\mathrm{p} K_{\mathrm{a}}$ value of $\mathrm{H}_{2} \mathrm{~S}$ is only 6.76 (65), indicating that, unlike GSH, about $80 \%$ of $\mathrm{H}_{2} \mathrm{~S}$ exists in its deprotonated form, $\mathrm{HS}^{-}$, at physiological $\mathrm{pH}$. Therefore, we hypothesized that this small molecular weight nucleophile may capture xenobiotic electrophiles, resulting in the formation of their sulfur adducts. Consistent with this notion, we identified bismethylmercury sulfide $(\mathrm{MeHg})_{2} \mathrm{~S}$ as a novel metabolite in SH-SY5Y cells exposed to $\mathrm{MeHg}$ and the liver of rats treated with $\mathrm{MeHg}$ (66). Using authentic $(\mathrm{MeHg})_{2} \mathrm{~S}$, it was also shown that these sulfur adducts are detoxified metabolites in vitro and in vivo (66).

Cystathionine $\beta$-synthase (CBS), cystathionine $\gamma$-lyase (CSE), and 3-mercaptopyruvate sulfurtransferase (3MST) have been considered as $\mathrm{H}_{2} \mathrm{~S}$-producing enzymes. How-

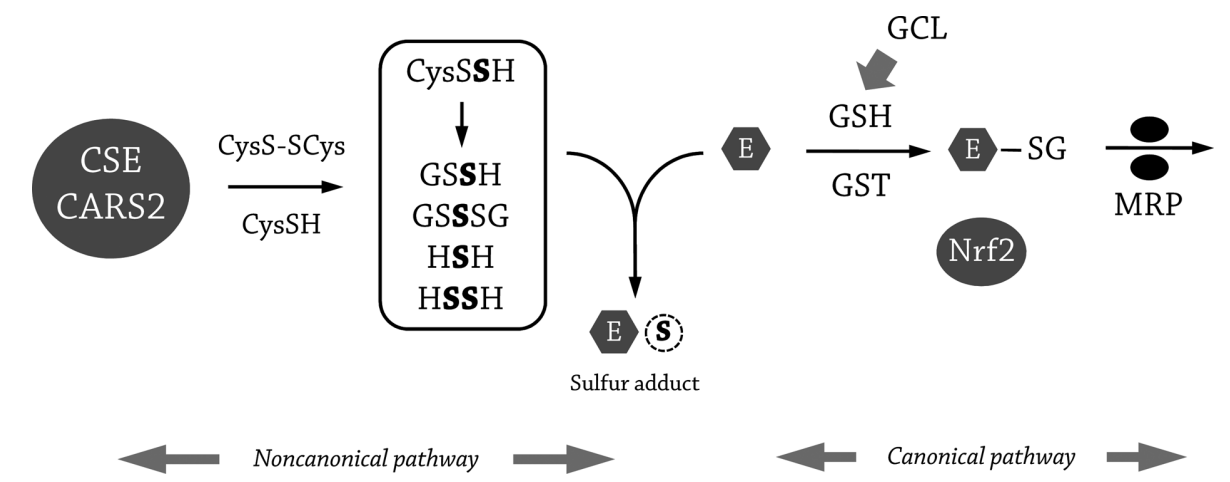

Fig. 3. Two defense systems against xenobiotic electrophiles. Canonical pathway: electrophiles conjugate with GSH to form electrophile-SG adducts that are rapidly excreted into the extracellular space. Nrf2 plays a critical role in the detoxification and excretion of electrophiles via GSH conjugation by initiating the transcription of GCL, GST, and MRP. Noncanonical pathway: reactive sulfur species produced by trans-sulfuration enzymes, such as CSE and CARS2, inactivate electrophiles through the formation of sulfur adducts. CARS2, cysteinyl-tRNA synthetase 2; CSE, cystathionine $\gamma$-lyase; GCL, glutamate-cysteine ligase; GST, glutathione S-transferase; MRP, multidrug resistance-associated protein; Nrf2, NF-E2-related factor 2. 
<smiles>CC(=O)Nc1ccc(O)c(SSSC(N)C(=O)O)c1</smiles>
$1,2-\mathrm{NQ}$<smiles>O=C1C(O)=C(S(=O)C2=C(O)C(=O)c3ccccc3C2=O)C(=O)c2ccccc21</smiles><smiles>O=C1C=C(S(=O)C2=CC(=O)c3ccccc3C2=O)C(=O)c2ccccc21</smiles><smiles>O=C1C=C(S)C(=O)c2ccccc21</smiles><smiles>O=C1C=C(S)c2ccccc2C1=O</smiles><smiles>O=C1C=C(SC2=CC(=O)C(=O)c3ccccc32)c2ccccc2C1=O</smiles>

$\mathrm{MeHg}$

MeHg-S-HgMe<smiles>CC(=O)Nc1ccc(O)c(SSCC(NC(=O)CCC(N)C(=O)O)C(=O)NCC(=O)O)c1</smiles><smiles>CC(=O)Nc1ccc(O)c(SSSC(N)C(=O)O)c1</smiles>

$\mathrm{Cd}$

CdS $\quad$ Cd-S-SO

Fig. 4. Sulfur adducts of xenobiotic electrophiles identified in our laboratory. Reactions of electrophiles with reactive sulfur species yield various sulfur adducts of electrophiles in vitro and in vivo.

ever, a collaborative study with Takaaki Akaike from Tohoku University, Japan reported that CBS and CSE catalyze vitamin $\mathrm{B}_{6}$-dependent formation of cysteine persulfide (CysSSH) derived from cysteine (CysSSCys) as a substrate (67). CysSSH spontaneously interacts with GSH, yielding GSH persulfide (GSSH), GSH polysulfide (GSSnH, $\mathrm{n}>2$ ), and $\mathrm{H}_{2} \mathrm{~S}$. This reaction suggests that the formation of these reactive sulfur species is due to the transfer of their intramolecular sulfane sulfur (zerovalent $\mathrm{S}$ atoms consisting of six valence electrons that are reversibly bound to other S atoms). GSSSG, the oxidized form of GSSH, was detected during the interaction of $\mathrm{CysSSH}$ with GSH. We found that GSSSG also served as a substrate for GSH reductase, suggesting a generating system for GSSH in vivo (67). Furthermore, a subsequent collaboration found that mitochondrial cysteine-tRNA synthetase (CARS2) also catalyzes the formation of CysSSH from CysSH (68), indicating that CARS2 is a multifunctional protein.

In addition to GSSH and $\mathrm{H}_{2} \mathrm{~S}$ participating in the formation of $(\mathrm{MeHg})_{2} \mathrm{~S}(69)$, we have identified numerous sulfur adducts of 1,2-NQ (70), 1,4-NQ (55), Cd (71), and Nacetyl-p-benzoquinone (NAPQI), an electrophilic metabolite of acetaminophen (72), as shown in Fig. 4. In particular, in the cases of 1,4-NQ and Cd, hardly any changes were observed in the redox signaling and toxicity caused by exposure to the parent compound for each sulfur adduct $(55,71)$. These studies describe a new detoxification system through the capture and inactivation by reac- tive sulfur species, which are different from the GSH adducts of electrophiles that have previously been known (Fig. 3).

\section{CONCLUSIONS}

Depending on our environment, lifestyle, and dietary habits, we are exposed to various doses of multiple environmental electrophiles. In 2005, Christopher Wild, who served as director of the International Agency for Research on Cancer (IARC) from 2009 to 2018, proposed the concept of the exposome to describe the totality of environmental exposures experienced by humans throughout their lifetime. Although exposomes are classified into general external, special external, and internal factors, it is considered that the differences in the dose and time of exposure may be related to health, presymptomatic illness, or disease. Focusing on the fact that highly reactive electrophiles are recognized as "priority components" in exposome research, and that environmental electrophiles with different structures are included among the chemicals, pollutants, diet, and lifestyle factors that constitute the special external factors, we have researched the environmental electrophile exposome as introduced here. Our expectation is that combined exposure to various electrophiles will cause each of these substances to covalently bond to the thiolate ions of the sensor protein, resulting in the activation of the response molecule at lower doses than indi- 
vidual exposure. Therefore, toxicity is expressed at a lower dose than individual exposure in response to lowering the sensitivity and response threshold during combined exposure. Thus, there is a need for combined exposure studies and reconsideration of the environmental risks. We also speculate that various modulations of redox signaling pathways and cytotoxicity are negatively regulated by reactive sulfur species through the formation of their sulfur adducts (Fig. 4).

\section{ACKNOWLEDGMENTS}

This work was supported by JSPS KAKENHI Grant Numbers JP18H05293 to Y. K., JP19K16368 to T. U., and JP18K14895 to M. A. We thank Mitchell Arico from Edanz Group (www.edanzediting.com/ac) for editing a draft of this manuscript.

\section{CONFLICT OF INTEREST}

The authors declare they have no actual or potential competing financial interests.

Received July 10, 2019; Revised August 21, 2019; Accepted August 26, 2019

\section{REFERENCES}

1. Eiguren-Fernandez, A., Miguel, A.H., Di Stefano, E., Schmitz, D.A., Cho, A.K., Thurairatnam, S., Avol, E.L. and Froines, J.R. (2008) Atmospheric distribution of gas- and particlephase quinones in Southern California. Aerosol Sci. Tech., 42, 854-861.

2. Chung, M.Y., Lazaro, R.A., Lim, D., Jackson, J., Lyon, J., Rendulic, D. and Hasson, A.S. (2006) Aerosol-borne quinones and reactive oxygen species generation by particulate matter extracts. Environ. Sci. Technol., 40, 4880-4886.

3. Jakober, C.A., Riddle, S.G., Robert, M.A., Destaillats, H., Charles, M.J., Green, P.G. and Kleeman, M.J. (2007) Quinone emissions from gasoline and diesel motor vehicles. Environ. Sci. Technol., 41, 4548-4554.

4. Shinyashiki, M., Eiguren-Fernandez, A., Schmitz, D.A., Di Stefano, E., Li, N., Linak, W.P., Cho, S.H., Froines, J.R. and Cho, A.K. (2009) Electrophilic and redox properties of diesel exhaust particles. Environ. Res., 109, 239-244.

5. Talhout, R., Schulz, T., Florek, E., van Benthem, J., Wester, P. and Opperhuizen, A. (2011) Hazardous compounds in tobacco smoke. Int. J. Environ. Res. Public Health, 8, 613628.

6. Reznick, A.Z., Cross, C.E., Hu, M.L., Suzuki, Y.J., Khwaja, S., Safadi, A., Motchnik, P.A., Packer, L. and Halliwell, B. (1992) Modification of plasma proteins by cigarette smoke as measured by protein carbonyl formation. Biochem. J., 286, 607-611.

7. Potter, T.L. and Fagerson, I.S. (1990) Composition of coriander leaf volatiles. J. Agr. Food Chem., 38, 2054-2056.
8. Wenzl, T., De La Calle, M.B. and Anklam, E. (2003) Analytical methods for the determination of acrylamide in food products: A review. Food Addit. Contam., 20, 885-902.

9. Koeman, J.H., van de Ven, W.S., de Goeij, J.J., Tjioe, P.S. and van Haaften, J.L. (1975) Mercury and selenium in marine mammals and birds. Sci. Total Environ., 3, 279-287.

10. Peterson, C.L., Klawe, W.L. and Sharp, G.D. (1973) Mercury in Tunas - Review. Fish. Bull. (Wash. D. C.), 71, 603-613.

11. Iwao, S., Sugita, M. and Tsuchiya, K. (1981) Some metabolic interrelationships among cadmium, lead, copper and zinc: results from a field survey in Cd-polluted areas in Japan. Part one: dietary intake of the heavy metals. Keio J. Med., 30, 17-36.

12. Bingham, F.T. (1979) Bioavailability of Cd to Food crops in relation to heavy metal content of sludge-amended soil. Environ. Health Perspect., 28, 39-43.

13. Fujiki, H. (2014) Gist of Dr. Katsusaburo Yamagiwa's papers entitled "Experimental study on the pathogenesis of epithelial tumors" (I to VI reports). Cancer Sci., 105, 143-149.

14. Borgen, A., Darvey, H., Castagnoli, N., Crocker, T.T., Rasmussen, R.E. and Wang, I.Y. (1973) Metabolic conversion of benzo(a)pyrene by Syrian hamster liver microsomes and binding of metabolites to deoxyribonucleic acid. J. Med. Chem., 16, 502-506.

15. Herenblum, I. (1945) 3:4-Benzpyrene from coal tar. Nature, 156, 601.

16. Costa, E., Karczmar, A.G. and Vesell, E.S. (1989) Bernard B. Brodie and the rise of chemical pharmacology. Annu. Rev. Pharmacol. Toxicol., 29, 1-21.

17. Brodie, B.B., Reid, W.D., Cho, A.K., Sipes, G., Krishna, G. and Gillette, J.R. (1971) Possible mechanism of liver necrosis caused by aromatic organic compounds. Proc. Natl. Acad. Sci. U.S.A., 68, 160-164.

18. Mitchell, J.R., Jollow, D.J., Potter, W.Z., Gillette, J.R. and Brodie, B.B. (1973) Acetaminophen-induced hepatic necrosis. IV. Protective role of glutathione. J. Pharmacol. Exp. Ther., 187, 211-217.

19. Friling, R.S., Bensimon, A., Tichauer, Y. and Daniel, V. (1990) Xenobiotic-inducible expression of murine glutathione S-transferase Ya subunit gene is controlled by an electrophile-responsive element. Proc. Natl. Acad. Sci. U.S.A., 87, 6258-6262.

20. Itoh, K., Wakabayashi, N., Katoh, Y., Ishii, T., Igarashi, K., Engel, J.D. and Yamamoto, M. (1999) Keap1 represses nuclear activation of antioxidant responsive elements by Nrf2 through binding to the amino-terminal Neh2 domain. Genes Dev., 13, 76-86.

21. Itoh, K., Chiba, T., Takahashi, S., Ishii, T., Igarashi, K., Katoh, Y., Oyake, T., Hayashi, N., Satoh, K., Hatayama, I., Yamamoto, M. and Nabeshima, Y. (1997) An Nrf2/small Maf heterodimer mediates the induction of phase II detoxifying enzyme genes through antioxidant response elements. Biochem. Biophys. Res. Commun., 236, 313-322.

22. Esterbauer, H., Schaur, R.J. and Zollner, H. (1991) Chemistry and biochemistry of 4-hydroxynonenal, malonaldehyde and related aldehydes. Free Radic. Biol. Med., 11, 81-128.

23. Schopfer, F.J., Cipollina, C. and Freeman, B.A. (2011) Formation and signaling actions of electrophilic lipids. Chem. Rev., 111, 5997-6021. 
24. Sawa, T., Zaki, M.H., Okamoto, T., Akuta, T., Tokutomi, Y., Kim-Mitsuyama, S., Ihara, H., Kobayashi, A., Yamamoto, M., Fujii, S., Arimoto, H. and Akaike, T. (2007) Protein Sguanylation by the biological signal 8-nitroguanosine 3 ',5'cyclic monophosphate. Nat. Chem. Biol., 3, 727-735.

25. Suzuki, T. and Yamamoto, M. (2017) Stress-sensing mechanisms and the physiological roles of the Keap1-Nrf2 system during cellular stress. J. Biol. Chem., 292, 16817-16824.

26. Ahmed, K.A., Sawa, T. and Akaike, T. (2011) Protein cysteine S-guanylation and electrophilic signal transduction by endogenous nitro-nucleotides. Amino Acids, 41, 123-130.

27. Kobayashi, E., Suzuki, T. and Yamamoto, M. (2013) Roles nrf2 plays in myeloid cells and related disorders. Oxid. Med. Cell. Longev., 2013, 529219.

28. Jones, D.P. (2008) Radical-free biology of oxidative stress. Am. J. Physiol. Cell Physiol., 295, C849-C868.

29. Kumagai, Y. and Abiko, Y. (2017) Environmental electrophiles: Protein adducts, modulation of redox signaling, and interaction with persulfides/polysulfides. Chem. Res. Toxicol., 30, 203-219.

30. Kumagai, Y., Shinkai, Y., Miura, T. and Cho, A.K. (2012) The chemical biology of naphthoquinones and its environmental implications. Annu. Rev. Pharmacol. Toxicol., 52, 221-247.

31. Sumi, D. (2008) Biological effects of and responses to exposure to electrophilic environmental chemicals. J. Health Sci., 54, 267-272.

32. Ahn, S.G. and Thiele, D.J. (2003) Redox regulation of mammalian heat shock factor 1 is essential for Hsp gene activation and protection from stress. Genes Dev., 17, 516-528.

33. Nishizawa, J., Nakai, A., Matsuda, K., Komeda, M., Ban, T. and Nagata, K. (1999) Reactive oxygen species play an important role in the activation of heat shock factor 1 in ischemic-reperfused heart. Circulation, 99, 934-941.

34. Itoh, K., Tong, K.I. and Yamamoto, M. (2004) Molecular mechanism activating Nrf2-Keap1 pathway in regulation of adaptive response to electrophiles. Free Radic. Biol. Med., 36, 1208-1213.

35. Ha, H.L. and Yu, D.Y. (2010) HBx-induced reactive oxygen species activates hepatocellular carcinogenesis via dysregulation of PTEN/Akt pathway. World J. Gastroenterol., 16, 4932-4937.

36. Tan, P.L., Shavlakadze, T., Grounds, M.D. and Arthur, P.G. (2015) Differential thiol oxidation of the signaling proteins Akt, PTEN or PP2A determines whether Akt phosphorylation is enhanced or inhibited by oxidative stress in $\mathrm{C} 2 \mathrm{C} 12$ myotubes derived from skeletal muscle. Int. J. Biochem. Cell Biol., 62, 72-79.

37. Tonks, N.K. (2003) PTP1B: From the sidelines to the front lines! FEBS Lett., 546, 140-148.

38. Lee, S.R., Kwon, K.S., Kim, S.R. and Rhee, S.G. (1998) Reversible inactivation of protein-tyrosine phosphatase $1 \mathrm{~B}$ in A431 cells stimulated with epidermal growth factor. $J$. Biol. Chem., 273, 15366-15372.

39. Tiganis, T. and Bennett, A.M. (2007) Protein tyrosine phosphatase function: The substrate perspective. Biochem. J., 402, 1-15.

40. Iwamoto, N., Sumi, D., Ishii, T., Uchida, K., Cho, A.K., Froines, J.R. and Kumagai, Y. (2007) Chemical knockdown of protein-tyrosine phosphatase 1B by 1,2-naphthoquinone through covalent modification causes persistent transactivation of epidermal growth factor receptor. J. Biol. Chem., 282, 33396-33404.

41. Abiko, Y. et al. Personal communication.

42. Yoshida, E., Kurita, M., Eto, K., Kumagai, Y. and Kaji, T. (2017) Methylmercury promotes prostacyclin release from cultured human brain microvascular endothelial cells via induction of cyclooxygenase-2 through activation of the EGFR-p38 MAPK pathway by inhibiting protein tyrosine phosphatase 1B activity. Toxicology, 392, 40-46.

43. Alam, J., Stewart, D., Touchard, C., Boinapally, S., Choi, A.M. and Cook, J.L. (1999) Nrf2, a Cap'n'Collar transcription factor, regulates induction of the heme oxygenase-1 gene. J. Biol. Chem., 274, 26071-26078.

44. Wild, A.C., Moinova, H.R. and Mulcahy, R.T. (1999) Regulation of gamma-glutamylcysteine synthetase subunit gene expression by the transcription factor Nrf2. J. Biol. Chem., 274, 33627-33636.

45. Chan, J.Y. and Kwong, M. (2000) Impaired expression of glutathione synthetic enzyme genes in mice with targeted deletion of the Nrf2 basic-leucine zipper protein. Biochim. Biophys. Acta, 1517, 19-26.

46. Hayashi, A., Suzuki, H., Itoh, K., Yamamoto, M. and Sugiyama, Y. (2003) Transcription factor Nrf2 is required for the constitutive and inducible expression of multidrug resistance-associated protein 1 in mouse embryo fibroblasts. Biochem. Biophys. Res. Commun., 310, 824-829.

47. Vollrath, V., Wielandt, A.M., Iruretagoyena, M. and Chianale, J. (2006) Role of Nrf2 in the regulation of the Mrp2 (ABCC2) gene. Biochem. J., 395, 599-609.

48. Maher, J.M., Dieter, M.Z., Aleksunes, L.M., Slitt, A.L., Guo, G., Tanaka, Y., Scheffer, G.L., Chan, J.Y., Manautou, J.E., Chen, Y., Dalton, T.P., Yamamoto, M. and Klaassen, C.D. (2007) Oxidative and electrophilic stress induces multidrug resistance-associated protein transporters via the nuclear factor-E2-related factor-2 transcriptional pathway. Hepatology, 46, 1597-1610.

49. Kalthoff, S., Ehmer, U., Freiberg, N., Manns, M.P. and Strassburg, C.P. (2010) Interaction between oxidative stress sensor Nrf2 and xenobiotic-activated aryl hydrocarbon receptor in the regulation of the human phase II detoxifying UDPglucuronosyltransferase 1A10. J. Biol. Chem., 285, 59936002.

50. Hirose, R., Miura, T., Sha, R., Shinkai, Y., Tanaka-Kagawa, T. and Kumagai, Y. (2012) A method for detecting covalent modification of sensor proteins associated with 1,4-naphthoquinone-induced activation of electrophilic signal transduction pathways. J. Toxicol. Sci., 37, 891-898.

51. Abiko, Y., Sha, L., Shinkai, Y., Unoki, T., Luong, N.C., Tsuchiya, Y., Watanabe, Y., Hirose, R., Akaike, T. and Kumagai, Y. (2017) 1,4-Naphthoquinone activates the HSP90/ HSF1 pathway through the S-arylation of HSP90 in A431 cells: Negative regulation of the redox signal transduction pathway by persulfides/polysulfides. Free Radic. Biol. Med., 104, 118-128.

52. Shinkai, Y., Masuda, A., Akiyama, M., Xian, M. and Kumagai, Y. (2017) Cadmium-mediated activation of the HSP90/ HSF1 pathway regulated by reactive persulfides/polysul- 
fides. Toxicol. Sci., 156, 412-421.

53. Stambolic, V., Suzuki, A., de la Pompa, J.L., Brothers, G.M., Mirtsos, C., Sasaki, T., Ruland, J., Penninger, J.M., Siderovski, D.P. and Mak, T.W. (1998) Negative regulation of $\mathrm{PKB} /$ Akt-dependent cell survival by the tumor suppressor PTEN. Cell, 95, 29-39.

54. Unoki, T., Abiko, Y., Toyama, T., Uehara, T., Tsuboi, K., Nishida, M., Kaji, T. and Kumagai, Y. (2016) Methylmercury, an environmental electrophile capable of activation and disruption of the Akt/CREB/Bcl-2 signal transduction pathway in SH-SY5Y cells. Sci. Rep., 6, 28944.

55. Abiko, Y., Shinkai, Y., Unoki, T., Hirose, R., Uehara, T. and Kumagai, Y. (2017) Polysulfide Na2S4 regulates the activation of PTEN/Akt/CREB signaling and cytotoxicity mediated by 1,4-naphthoquinone through formation of sulfur adducts. Sci. Rep., 7, 4814.

56. Unoki, T., Akiyama, M., Kumagai, Y., Goncalves, F.M., Farina, M., da Rocha, J.B.T. and Aschner, M. (2018) Molecular pathways associated with methylmercury-induced Nrf2 modulation. Front. Genet., 9, 373.

57. Endo, A., Sumi, D., Iwamoto, N. and Kumagai, Y. (2011) Inhibition of DNA binding activity of cAMP response element-binding protein by 1,2-naphthoquinone through chemical modification of Cys-286. Chem. Biol. Interact., 192, 272-277.

58. Lu, S.C. (2013) Glutathione synthesis. Biochim. Biophys. Acta, 1830, 3143-3153.

59. Armstrong, R.N. (1991) Glutathione S-transferases: reaction mechanism, structure, and function. Chem. Res. Toxicol., 4, 131-140.

60. Eggler, A.L., Liu, G., Pezzuto, J.M., van Breemen, R.B. and Mesecar, A.D. (2005) Modifying specific cysteines of the electrophile-sensing human Keap1 protein is insufficient to disrupt binding to the Nrf2 domain Neh2. Proc. Natl. Acad. Sci. U.S.A., 102, 10070-10075.

61. Ketterer, B., Coles, B. and Meyer, D.J. (1983) The role of glutathione in detoxication. Environ. Health Perspect., 49, 59-69.

62. Gum, S.I. and Cho, M.K. (2013) Recent updates on acetaminophen hepatotoxicity: the role of nrf2 in hepatoprotection. Toxicol. Res., 29, 165-172.

63. Polhemus, D.J., Calvert, J.W., Butler, J. and Lefer, D.J. (2014) The cardioprotective actions of hydrogen sulfide in acute myocardial infarction and heart failure. Scientifica (Cairo), 2014, 768607.

64. Polhemus, D.J. and Lefer, D.J. (2014) Emergence of hydro- gen sulfide as an endogenous gaseous signaling molecule in cardiovascular disease. Circ. Res., 114, 730-737.

65. Hughes, M.N., Centelles, M.N. and Moore, K.P. (2009) Making and working with hydrogen sulfide: The chemistry and generation of hydrogen sulfide in vitro and its measurement in vivo: a review. Free Radic. Biol. Med., 47, 13461353.

66. Yoshida, E., Toyama, T., Shinkai, Y., Sawa, T., Akaike, T. and Kumagai, Y. (2011) Detoxification of methylmercury by hydrogen sulfide-producing enzyme in Mammalian cells. Chem. Res. Toxicol., 24, 1633-1635.

67. Ida, T., Sawa, T., Ihara, H., Tsuchiya, Y., Watanabe, Y., Kumagai, Y., Suematsu, M., Motohashi, H., Fujii, S., Matsunaga, T., Yamamoto, M., Ono, K., Devarie-Baez, N.O., Xian, M., Fukuto, J.M. and Akaike, T. (2014) Reactive cysteine persulfides and S-polythiolation regulate oxidative stress and redox signaling. Proc. Natl. Acad. Sci. U.S.A., 111, 76067611.

68. Akaike, T., Ida, T., Wei, F.Y., Nishida, M., Kumagai, Y., Alam, M.M., Ihara, H., Sawa, T., Matsunaga, T., Kasamatsu, S., Nishimura, A., Morita, M., Tomizawa, K., Nishimura, A., Watanabe, S., Inaba, K., Shima, H., Tanuma, N., Jung, M., Fujii, S., Watanabe, Y., Ohmuraya, M., Nagy, P., Feelisch, M., Fukuto, J.M. and Motohashi, H. (2017) Cysteinyl-tRNA synthetase governs cysteine polysulfidation and mitochondrial bioenergetics. Nat. Commun., 8, 1177.

69. Abiko, Y., Yoshida, E., Ishii, I., Fukuto, J.M., Akaike, T. and Kumagai, Y. (2015) Involvement of reactive persulfides in biological bismethylmercury sulfide formation. Chem. Res. Toxicol., 28, 1301-1306.

70. Nishida, M., Sawa, T., Kitajima, N., Ono, K., Inoue, H., Ihara, H., Motohashi, H., Yamamoto, M., Suematsu, M., Kurose, H., van der Vliet, A., Freeman, B.A., Shibata, T., Uchida, K., Kumagai, Y. and Akaike, T. (2012) Hydrogen sulfide anion regulates redox signaling via electrophile sulfhydration. Nat. Chem. Biol., 8, 714-724.

71. Akiyama, M., Shinkai, Y., Unoki, T., Shim, I., Ishii, I. and Kumagai, Y. (2017) The capture of cadmium by reactive polysulfides attenuates cadmium-induced adaptive responses and hepatotoxicity. Chem. Res. Toxicol., 30, 2209-2217.

72. Abiko, Y., Ishii, I., Kamata, S., Tsuchiya, Y., Watanabe, Y., Ihara, H., Akaike, T. and Kumagai, Y. (2015) Formation of sulfur adducts of N-acetyl-p-benzoquinoneimine, an electrophilic metabolite of acetaminophen in vivo: Participation of reactive persulfides. Chem. Res. Toxicol., 28, 1796-1802. 